\title{
Importance of the methanogenic archaea populations in anaerobic wastewater treatments.
}

\begin{abstract}
Methane derived from anaerobic treatment of organic wastes has a great potential to be an alternative fuel. Abundant biomass from various industries could be a source for biomethane production where combination of waste treatment and energy production would be an advantage. This article summarizes the importance of the microbial population, with a focus on the methanogenic archaea, on the anaerobic fermentative biomethane production from biomass. Types of major wastewaters that could be the source for biomethane generation such as brewery wastewater, palm oil mill effluent, dairy wastes, cheese whey and dairy wastewater, pulp and paper wastewaters and olive oil mill wastewaters in relevance to their dominant methanogenic population are fully discussed in this article.
\end{abstract}

Keyword: Biomethane; Biomass; Methanogens; Anaerobic treatment; Wastewater 